\title{
O processo produtivo artesanal analisado sob o enfoque de inovações sociais: um estudo de caso na cadeia produtiva da moda
}

\author{
The artisanal production process analyzed under the social innovations \\ approach: a case study in the fashion production chain
}

\section{Le processus de production artisanale analysé du point de vue des innovations sociales: une étude de cas dans la chaîne de production de la mode}

\author{
El proceso de producción artesanal analizado desde el punto de vista de las
} innovaciones sociales: un estudio de caso en la cadena de producción de la moda

\author{
Aline Silva Autran de Morais ${ }^{1}$ \\ Simone Sehnem ${ }^{1}$ \\ Aléssio Bessa Sarquis ${ }^{1}$ \\ Taisa Dias ${ }^{1}$
}

Recebido em 22/12/2016; revisado e aprovado em 15/04/2017; aceito em 02/06/2017

DOI: http://dx.doi.org/10.20435/inter.v18i4.1459

\begin{abstract}
Resumo: Este artigo analisa se, na relação entre a rede de produção com artesãos, no contexto da cadeia têxtil da empresa Catarina Mina, há promoção do bem-estar e geração de mudança qualitativa na comunidade das artesãs locais pelo incentivo e apoio ao trabalho manual. Os resultados indicam que, embora tenha alguma inovação, o projeto não pode ser enquadrado no conceito da inovação social, por ter forte dependência da gestora, não atender plenamente os requisitos necessários e por ainda não promover o empowerment e a transformação da comunidade.
\end{abstract}

Palavras-chave: inovações sociais; cadeia produtiva de moda; artesãos.

Abstract: This article analyzes if, in the relationship between the production network with artisans in the context of the textile chain of the company Catarina Mina, there is a promotion of the well-being and generation of qualitative change in the community of the local artisans from the encouragement and support to the manual work. The results indicate that, although the project has some innovation, it cannot be included in the concept of social innovation, because it has a strong dependence on the manager, does not fully meet the necessary requirements, and does not yet promote empowerment and community transformation.

Key words: social innovations; fashion productive chain; artisan.

Résumé: Cet article examiné se la relation entre le réseau de production avec des artisans dans le cadre de la chaîne textile en la entreprise Catarina Mina Il y a une promotion du bien-être et générer des changements qualitatifs dans la communauté des artisans locaux en encourageant et en soutenant le travail manuel. Les résultats indiquent que, bien que le projet a une certaine innovation ne peut pas être encadrée dans le concept d'innovation sociale car il a une forte dépendance du gestionnaire ne répond pas pleinement aux exigences et ne favorise pas la responsabilisation et la transformation de la communauté.

Mots-clés: innovations sociales; chaine de production de mode; artisanes.

Resumen: Este artículo analiza si en la relación entre la red de producción con artesanos, en el contexto de la cadena textil de la empresa Catarina Mina, hay promoción del bienestar y generación de cambio cualitativo en la comunidad de las artesanas locales por el incentivo y apoyo al trabajo manual. Los resultados indican que, aunque el proyecto tiene alguna innovación, no puede ser encuadrado en el concepto de la innovación social, pues tiene fuerte dependencia de la gestora, no atiende plenamente los requisitos necesarios y por no promover el empoderamiento y la transformación de la comunidad.

Palabras clave: innovaciones sociales; cadena de producción de moda; artesanos.

\footnotetext{
${ }^{1}$ Universidade do Sul de Santa Catarina (UNISUL), Florianópolis, Santa Catarina, Brasil.
} 


\section{INTRODUÇÃO}

No Brasil, o artesanato é uma das formas de manifestação cultural e está presente em 64,3\% dos municípios, principalmente nos estados do Acre, Amazonas, Ceará, Pernambuco, Alagoas, Espírito Santo, Santa Catarina, Rio Grande do Sul, Mato Grosso do Sul e Rio de Janeiro (DUARTE; SILVA, 2013). No país, por ter tradição cultural e turística, a região Nordeste se destaca pela variedade de artesanatos e pela expressividade da produção.

Coutinho e Ferraz (1993) analisaram a competitividade da indústria brasileira no setor de têxteis, vestuários e calçados, e concluíram que há deficiências competitivas e necessidade de mudança no relacionamento com fornecedores. Revelou, também, que o trabalho manual dos artesãos é, ainda, pouco valorizado pelos consumidores. Sobre o assunto, Lourenço (2014) afirmou que, no Brasil, a desvalorização do trabalho manual tem raízes nos traços da cultura e porque este é associado à atividade servil. Em geral, o trabalho dos artesões na indústria da confecção é feito por senhoras de idade mais avançada, há pouco incentivo financeiro e sem contrato de trabalho. Isso tende a reduzir o interesse das novas gerações nessa atividade/ofício.

Dados do Instituto Brasileiro de Geografia e Estatística (IBGE) indicam que, no Brasil, o artesanato é um setor onde há exclusão social, com baixo rendimento econômico, baixa escolaridade e informalidade (FREEMAN, 2011). Um dos principais desafios enfrentados pelos artesãos do Programa de Artesanato Brasileiro, do Ministério do Desenvolvimento, Indústria e Comércio Exterior (MDIC), que visa à geração de trabalho e à melhoria do nível cultural, social e econômico do artesão brasileiro, é a comercialização dos produtos/artesanato. Sabe-se que apenas $5 \%$ deles conseguem vender por meio de lojas físicas, e $1 \%$ deles por meio de lojas virtuais (FREEMAN, 2011). A grande maioria deles carece de conhecimentos em vendas e acesso a canais de distribuição.

Como ocorreu em outros setores da economia, no Brasil o crescimento das importações gerou transformações na cadeia produtiva de moda. Houve diminuição na produção de artigos da indústria têxtil e aumento na aquisição de produtos provenientes de outros países com menor custo de produção, como a China (UNIETHOS, 2013). Para manter a competitividade de mercado, os varejistas brasileiros buscaram novos fornecedores, que oferecem menor custo, mesmo que careçam de soluções inovadoras que beneficiem a cadeia de fornecimento. Rech (2009) apontou que a cadeia de fornecimento desse setor necessita desenvolver atitudes proativas no processo de gestão, melhorar o relacionamento com fornecedores, comunidades, órgãos competentes e demais atores envolvidos, e garantir a sustentabilidade do setor. Essas mudanças requerem maior participação dos atores envolvidos e investimentos em inovação social.

A inovação social é definida como mudanças/melhorias promovidas por organização ou entidade, de natureza interna ou externa, com o propósito de atender necessidades de grupos sociais ou da comunidade, e que contribuam para o empowerment e valorização de indivíduos, com a cooperação dos diferentes atores envolvidos (BIGNETTI, 2011). Melo Lisboa (2005) ressaltou que a inovação social precisa promover a coesão social, possibilitar a inserção de pessoas desfavorecidas e promover o desenvolvimento de municípios envolvidos. Para Cloutier (2003), essas transformações sociais precisam ser, também, perenes e representar mudanças nas relações e condições sociais, e ter a cooperação intensa dos atores envolvidos. Já Mulgan, Tucker e Sanders (2007) afirmaram que, na inovação social, é essencial o papel crítico dos atores envolvidos e a integração de pessoas, ideias, recursos e poder, pois isto contribui para a perenidade das mudanças e para o atendimento das necessidades sociais desejadas. 
Diante desse contexto, ciente dos problemas na cadeia produtiva de moda, da falta de valorização e incentivo do trabalho das artesãs e da necessidade de analisar a inovação social na rede de produção na cadeia têxtil, decidiu-se estudar o assunto com a seguinte questão de pesquisa: Há inovação social no contexto da rede de produção com artesãos na cadeia têxtil? Assim, este artigo visa analisar se há inovação social no contexto da rede de produção com artesãos na loja virtual Catarina Mina. Os objetivos específicos são: identificar como é feito o trabalho da loja Catarina Mina junto às artesãs; verificar se as artesãs se sentem reconhecidas, valorizadas e com melhorias na situação financeira; identificar se o incentivo na cadeia produtiva possibilitou melhorias sustentáveis na qualidade de vida das artesãs.

Este artigo apresenta a seguir a fundamentação teórica sobre artesãos e inovação social. Depois, contém os aspectos metodológicos envolvidos na realização do estudo empírico. Adiante, contém a apresentação e análise dos resultados obtidos. Por fim, as considerações finais, com as limitações do estudo e recomendações para futuras pesquisas sobre o tema.

\section{CONCEITUAÇÃO, VALORIZAÇÃO E INCENTIVO A ARTESÃOS}

Há diferentes visões/definições sobre artesões. No Brasil, o Ministério do Desenvolvimento, Indústria e Comércio Exterior (MDIC, 2010) define artesões como indivíduos que produzem artesanato, utilizando técnica predominantemente manual e/ou com auxílio de equipamentos, mas sem operar em sistemas de produção em série ou automática. Algumas formas de organização de artesãos são núcleos, associações ou cooperativas de artesãos. Pereira (1979) conceituou o artesanato como atividade predominantemente manufatureira, de transformação de matéria- prima em produtos acabados e caracterizada por certo grau de originalidade ou tipicidade. Já Chiavenato (2012) entende o artesanato como um sistema de produção unitário, que carece de mão de obra e com pouca padronização e automatização.

Em decorrência do processo de globalização e deslocamento das fabricas para regiões com menor custo de produção, o mercado da indústria de artesanato enfrenta elevação da competição e maior dificuldade para comercialização dos produtos (RECH, 2009; SACHS, 2008). Freeman (2011) comentou que as fábricas se apropriam rapidamente da estética/inovação no artesanato e reproduzem a sua aparência/design, disponibilizando para o mercado produtos feitos em escala de produção. No entanto, conforme Sachs (2008), o artesanato é, ainda, uma oportunidade de trabalho e resgate pessoal para as artesãs. A globalização trouxe, também, o valor do trabalho manual e do artesanato, pois este possibilita o resgate cultural e da identidade regional nos produtos (SERVIÇO DE APOIO ÀS MICRO E PEQUENAS EMPRESAS [SEBRAE], 2008). Sobre o assunto, Safar e Castro (2011) revelaram que uma das poucas alternativas de sobrevivência no mercado do artesanato é a oferta de produtos que tenham valor pelo uso de elementos singulares do repertório cultural de dada nação ou região.

No Brasil, na cadeia produtiva de moda, o trabalho manual é ainda pouco valorizado. Embora haja grandes empresas no mercado, o artesanato é predominantemente realizado por pequenas empresas e/ou artesões, e em regime de trabalho informal. Além disso, conforme Lourenço (2014), o brasileiro tende a valorizar mais o trabalho intelectual do que o trabalho manual. Para Freeman (2011), é necessário a conscientização do artesão sobre a importância da atividade/artesanato no panorama cultural e socioeconômico do país. Com isso, pode-se melhor comercializar o artesanato a preço justo, fomentar o desenvolvimento de parcerias e aperfeiçoar a gestão de associações e meios de produção. Outro fator relevante é a inclusão digital dos ar- 
tesãos, que pode ampliar as possibilidades de inserção no mercado e aumento de visibilidade, valorização e credibilidade. Entretanto o artesanato tende a ter um preço de venda elevado no mercado (quando comparado ao produto produzido em série), o que dificulta o volume de vendas e requer uma identidade mais forte com a comunidade e diversidade cultural (FREEMAN, 2011).

Duarte e Silva (2013) consideram o artesanato como um fator de valorização das tradições locais e como um propulsor da classe de trabalhadores e de pequenos empreendedores, pois permite a geração de ocupação profissional, renda e desenvolvimento local. A participação dos artesãos no planejamento, acompanhamento e avaliação de programas elaborados por entidades externas propiciaria o desenvolvimento de habilidades de planejamento e de negociação, e capacidades de autogestão e de gestão compartilhada, assim como de práticas democráticas (FREEMAN, 2011). No entanto esses programas precisam apoiar efetivamente o trabalho dos artesãos e promover o desenvolvimento sustentável, de forma que estes se mantenham mesmo ao final de projetos/programas de incentivo implementados. Tais programas precisam incluir, também, ações de capacitação para formação de parcerias com elos subjacentes à cadeia produtiva do artesanato, promover o desenvolvimento de produtos, embalagens, o preparo de matérias-primas, estocagem, a produção artesanal, a criação de identidade visual e investimentos em ações de marketing, venda e distribuição (FREEMAN, 2011).

O setor de artesanato promove a inserção da mulher e do adolescente em atividades produtivas, estimula a prática do associativismo e atenua (mesmo que com impacto reduzido) o crescimento desordenado dos centros urbanos, pois pode fixar o artesão no seu local/região de origem (SEBRAE, 2008). O estudo de Safar e Castro (2011) revelou que a revitalização do artesanato, a partir das referências locais e do aproveitamento do conhecimento empírico dos artesãos, eleva a autoestima dos artesãos e estimula positivamente a comunidade. Há, no entanto, desafios a serem vencidos, como a dificuldade de conquista de mercado e de agregação constante de valor aos produtos, ou seja, oferecer mais benefícios aos clientes. Okada e Berlim (2014) afirmaram que trabalhos manuais, de processamento não industrializados e produzidos em pequena escala, poderiam ser incentivados por um designer ativista, por agente comunicador na internet ou por empreendedor facilitador da atividade, pessoas que incentivem a diversidade de negócios e fortaleçam o compromisso com a comunidade.

\subsection{Inovação social}

A inovação social pode ser entendida como "o resultado do conhecimento aplicado a necessidades sociais através da participação e da cooperação de todos os atores envolvidos, gerando soluções novas e duradouras para grupos sociais, comunidades ou para a sociedade em geral" (BIGNETTI, 2011, p. 4). Cloutier (2003) a define tanto pela inovação em produtos ou em processos, como por seu impacto social positivo. Há diversas definições de inovação social, mas a maioria delas reconhece que é uma ação/atividade que envolve a cooperação de vários atores envolvidos, que gera consequências sociais positivas e que produz mudanças em um determinado território/região (CLOUTIER, 2003).

Mulgan, Tucker e Sanders (2007) diferenciam inovação social de inovação nos negócios. A primeira compreende novas ideias que funcionam para alcançar metas sociais e predominantemente desenvolvidas por organizações/entidades com objetivos sociais. Já a segunda é a inovação motivada para obter a maximização do lucro. Algumas características da inovação social são: serviços ou atividades realizadas por organizações sociais, governos e/ou outros atores, com

INTERAÇÕES, Campo Grande, MS, v. 18, n. 4, p. 121-135, out./dez. 2017. 
propósito de promover a satisfação humana e atender necessidades sociais, e cujos resultados sejam melhorias na qualidade de vida e no desenvolvimento territorial/comunidade.

A inovação social gera, inicialmente, impacto no ambiente local, mas tende posteriormente a causar impacto social significativo e mais amplo na sociedade. Ela demanda um processo coletivo de criação, aprendizagem e invenção, que transforma a realidade existente e que estabelece novas práticas sociais, com impacto sustentável na qualidade de vida da sociedade (FACHINELLI; D'ARISBO; MACIEL; 2014).

Segundo Cloutier (2003), a inovação social pode ajudar a resolver problemas econômicos e sociais relevantes ou melhorar a qualidade de vida por meio do sistema de produção de uma empresa/organização, contribuindo para modificar valores, crenças e representações partiIhadas na sociedade. O conceito de inovação social pode ser entendido em quatro dimensões (CLOUTIER, 2003): objeto em si e sua natureza (seja pela sua tangibilidade, caráter inovador e objetivo global); processo de criação e implementação (que identifica a diversidade de atores e a participação dos usuários); alvo de mudança (seja no nível individual, buscando desenvolver a capacidade; no espaço/território, buscando desenvolver determinada área/região; no local de trabalho/empresa, buscando promover mudança na estrutura de produção e melhora na qualidade de vida das pessoas); resultados (pois gera mudanças na sociedade, de forma duradoura e superior à prática de gestão/comércio tradicional).

Cloutier (2003) identificou três dimensões na inovação social, que seriam a tangibilidade, a novidade e o objetivo global. O seu caráter inovador pode ser medido pela extensão e profundidade das mudanças que as ações provocam no sistema, seja em termos de bem-estar de indivíduos e/ou da comunidade; que o processo de inovação social envolve aprendizagem e criação de conhecimento e deve ter diversidade de atores e a participação dos usuários. A cooperação entre os diferentes atores é fundamental, seja através de alianças estratégicas, parcerias ou redes de equipes multidisciplinares, pois proporciona pluralidade de pontos de vistas e a obtenção de imagem mais completa do problema, causas e possíveis soluções.

De acordo com Mulgan, Tucker e Sanders (2007), o primeiro passo na inovação social é a identificação de uma necessidade mal atendida ou não atendida, e de uma ideia apropriada de como atendê-la adequadamente. O segundo passo é testar a ideia para verificar a viabilidade e eventuais falhas e necessidades de melhorias. O terceiro passo é alimentar a ideia, ampliá-la, replicá-la e adaptá-la em outras realidades. O passo final é a consolidação da ideia em torno de alguns princípios fundamentais à medida que esta esteja sendo implementada em novos contextos.

As mudanças promovidas pela inovação social podem ocorrer em três lentes: indivíduos, movimentos sociais e organizações (MULGAN; TUCKER; SANDERS, 2007). Sabe-se que as mudanças sociais iniciais foram impulsionadas por pequena quantidade de indivíduos persistentes e dedicados, com capacidade de comunicar ideias complexas, de forma atraente e implementá-las (lente indivíduos). As inovações sociais têm, na fase inicial, um crescimento lento e um pequeno grupo de partidários comprometidos; já na fase seguinte, quando da evolução da implementação, há tendência de rápida decolagem; na fase final, ocorre a desaceleração, quando se atinge a maturidade ou saturação da ideia. A inovação é bem-sucedida quando consegue plantar a ideia em muitas mentes e por longo prazo, de forma mais poderosa do que indivíduos ou instituições específicas (lente movimentos sociais). Tais movimentos fomentam o empowerment das pessoas e fazem com que estas possam resolver seus próprios problemas (MULGAN, 2006). 
A inovação social pode, também, ocorrer no nível da organização. Muitas inovações surgem no contexto de organizações que querem se renovar e focadas em atividades, seja existentes, emergentes e/ou radicais. Para que as ideias possam obter sucesso, precisam ter o apoio de líderes da organização e se adaptarem às condições locais; podem carecer de alianças entre líderes e grupos, e/ou operar no espaço entre a política e a sociedade civil. Geralmente essas organizações trabalham com um mix diferente de recursos, incluindo reconhecimento político, trabalho voluntário e compromisso filantrópico (MULGAN; TUCKER; SANDERS, 2007).

As inovações sociais seguem mecanismos de transposição de experiências que favorecem a replicação e a expansão dos resultados para outras comunidades (BIGNETTI, 2011). Seus resultados trazem novas relações sociais entre indivíduos e grupos, e contribuem para a difusão da inovação, alimentando novas soluções sociais. Maurer e Silva (2014) afirmam que, na inovação social, os atores aprendem novos conhecimentos e habilidades através da formação profissional e da troca de informações, e que o aprendizado coletivo gera novas regras e padrões sociais.

Por fim, conforme Juliani et al. (2014), existe atualmente uma crescente busca por métodos alternativos de solução de problemas sociais e a inovação social pode contribuir para suprir as desigualdades sociais, problemas de sustentabilidade e questões ambientais. Sobre isso, Mulgan, Tucker e Sanders (2007) afirmaram que os mercados comerciais podem, também, promover novas ideias sociais, formando pequenas empresas dentro de seus próprios nichos, seja no espaço entre a sociedade civil, o governo e a empresa, e atraindo pensadores do campo, pequenas organizações do mundo do design, academia e comunidade, com ações convergentes e grupos de colaboração para trabalhar em problemas comuns. Para Okada e Berlim (2014), as inovações sociais podem mudar o modo como se faz o design de moda, de maneira mais sustentável, transitando em contextos sociais, apoiando-se em valores culturais e em experiências práticas, e melhorando a vida cotidiana das pessoas. Tais inovações podem favorecer o senso de comunidade, a solidariedade e modo de vida mais sustentáveis da sociedade.

\section{ASPECTOS METOdOLÓGICOS}

O presente estudo classifica-se como exploratório, com abordagem qualitativa e enfoque descritivo (CRESSWELL, 2010); compreende também um estudo de caso único, como classificado por Yin (2010). Utilizou-se a estratégia de estudo de caso tendo em vista o propósito de analisar em detalhes um fenômeno da vida real, contemporâneo e multifacetado.

O objeto de estudo é a empresa Catarina Mina, uma loja virtual do setor de bolsas femininas, localizada no Estado do Ceará. A unidade de análise é o Projeto de Incentivo na Cadeia Produtiva das Artesãs em Comunidades, promovido pela empresa na região da Grande Fortaleza, CE. Essa empresa foi escolhida porque tem projeto de incentivo às artesãs no âmbito da sua cadeia produtiva e aceitou voluntariamente a participar do estudo. A empresa atua com cinco profissionais diretos (funcionários contratados) e 15 profissionais indiretos (artesões terceirizados). As fontes de informação foram: proprietária da empresa, responsável pelas redes sociais, artesã de criação e seis artesãs que trabalham no projeto de incentivo às artesãs (total de nove entrevistados). O processo de seleção de amostra é por julgamento, e os elementos amostrais entrevistados foram os envolvidos no projeto.

A fase de coleta/campo envolveu a obtenção de dados primários e secundários. Os dados primários foram coletados pelas técnicas entrevista em profundidade e observação direta. A 
entrevista foi aplicada de maneira pessoal e individualizada, e apoiada com roteiro de entrevista semiestruturado. Foram aplicados três roteiros de entrevista: um com perguntas para a proprietária da empresa, outro para funcionários e outro para artesãs terceirizadas. Os roteiros de entrevista foram elaborados a partir dos objetivos do estudo e dos trabalhos de Cloutier (2003) e Mulgan, Tucker e Sanders (2007).

Já a observação direta foi utilizada como método completar na coleta de dados e foi empregada de maneira não estruturada, mas envolveu o registro em campo de fatos/evidências visuais, durante visita pessoal à empresa estudada. Os aspectos observados foram: o trabalho das artesãs no projeto; evidências de como são pensadas, discutidas e tomadas às decisões/ estratégias; evidências de participação de outras organizações ou do governo na formulação, discussão e acompanhamento das estratégias/ações das artesãs; existência de programas ou projetos de capacitação das artesãs e de incentivos/valorização das artesãs.

A coleta de dados secundários foi feita por meio de levantamento documental e envolveu a coleta de materiais/documentos disponibilizados pela empresa (como folders, revistas, jornais que publicaram matérias sobre a Catarina Mina) e a pesquisa eletrônica em websites e vídeos disponíveis na internet. Houve preocupação com a triangulação na coleta de dados, tanto no método de coleta (entrevista pessoal, observação direta e levantamento documental) como nas fontes de informação (proprietários, funcionários e terceirizados), como recomenda o Yin (2010). A coleta de dados foi realizada em agosto/2015.

A técnica de análise utilizada foi a análise de conteúdo, na forma qualitativa e por categorização temática de dados, como proposta por Bardin (1977). As entrevistas foram inicialmente transcritas literalmente. Depois ocorreu a leitura de verificação e a organização dos dados visuais, secundários e depoimentos coletados em categorias temáticas à luz das premissas de inovação social preconizadas por Cloutier (2003) e Mulgan, Tucker e Sanders (2007). As categorias de dados analisados foram: funcionamento da cadeia de produção de moda, incentivo à produção de moda da empresa, reconhecimento e valorização das artesãs, eficácia do incentivo à produção das artesãs, legitimidade e empoderamento das artesãs.

\section{APRESENTAÇÃO E ANÁLISE DOS RESULTADOS}

\subsection{Apresentação do objeto de estudo}

A Catarina Mina é uma loja virtual de bolsas fundada em 2005. A empresa está situada na cidade de Fortaleza, e os grupos de artesãs, no bairro do Morro de Santa Terezinha, local que já foi ponto de encontro de cearenses, turistas e cartão postal da cidade, mas hoje é um bairro popular, e na cidade de Itaitinga. A cidade fica a $32 \mathrm{~km}$ de Fortaleza, tendo maior concentração populacional na zona rural. Em 2010, 38,4\% da população foi classificada como de pobres e extremamente pobres (ITAITINGA, 2014).

A ideia da proprietária era fugir dos modelos de produção padronizados (e de produtos pouco atraentes) e produzir peças em crochê, renda, chita e metais. Associaram-se a alguns grupos de artesãos, instituições e ONGs em alguns projetos esporádicos no Ceará (FELIPPSEN, 2012). Com o passar do tempo, além da marca própria, operavam com private labels (marcas) de outras empresas. No início de 2015, a proprietária iniciou um novo projeto, denominado \#Uma Conversa Sincera, onde junta o design com o artesanato e nova forma de relacionamento com as artesãs.

INTERAÇÕES, Campo Grande, MS, v. 18, n. 4, p. 121-135, out./dez. 2017. 
Como, no Brasil, a marca foi a primeira a ter seus custos abertos para o consumidor final, apresentados detalhados na internet, e com propósito de valorizar o trabalho das artesãs, o projeto foi considerado pela empresa como inovador e pioneiro. A ideia básica inicial do projeto era menos esforço financeiro na exposição da marca e mais dedicação/reconhecimento ao trabalho das artesãs. Para as artesãs, o trabalho de artesanato é interessante, pois possibilita trabalhar em casa, no tempo e ritmo desejados, e obter uma renda mensal (mesmo que conforme volume de produção). Além disto, a proposta é disponibilizar para o cliente/consumidor o que tem perto de casa, valorizando a proximidade do fornecimento do produto ao invés da busca por produtos da China (CATARINA MINA, s.d.).

\subsection{Como é feito o trabalho pela Catarina Mina}

Dados coletados a partir de observação direta, levantamento documental e entrevista em profundidade possibilitaram compreender como é feito o trabalho na empresa Catarina Mina. As evidências indicam que a maioria das artesãs que trabalham para a empresa é de Itaitinga/Ceará e fazem parte da Associação dos Produtores de Artesanato e Confecção de Itaitinga (APACI), uma associação privada fundada em 2000. Embora a sede ainda exista, a associação perdeu força e atualmente não desenvolve atividades. As artesãs trabalham em casa e não possuem atividade na associação.

As artesãs entrevistadas trabalham na produção de bolsas e são terceirizadas; somente a artesã da criação é funcionária da empresa. O trabalho é feito de acordo com a disponibilidade das artesãs. Algumas mantêm outras atividades paralelas, como costura e agricultura, e normalmente são senhoras de mais idade. Alguns depoimentos das artesãs indicam que a nova geração não tem interesse nesse tipo de atividade, como citado por Lourenço (2014).

Outro fator importante que foi identificado é que a competição internacional (COUTINHO; FERRAZ, 1994; RECH, 2009; SACHS, 2008) foi um dos motivadores para a proprietária da empresa decidir criar esse projeto de incentivo/valorização do artesanato. O projeto é visto como contrapartida à massificação de produtos (resultado da globalização e do sistema de produção em série) e um contraponto ao fast fashion, moda rápida (SEBRAE, 2008). O trabalho manual das artesãs parece ser incentivado pelo designer ou pela proprietária da empresa, que fortalecem o sentimento de comunidade (OKADA; BERLIM, 2014).

O projeto é uma iniciativa da proprietária da Catarina Mina, e não existe participação de governo ou outras organizações. Tem, no entanto, a colaboração de algumas empresas privadas parceiras, que ajudam na divulgação do projeto e dos produtos. O projeto foi financeiramente viabilizado por financiamento do Banco do Nordeste. Não existem programas nem projetos de capacitação, mas apoio à produção de produtos e ensinamentos sobre as peças, quando necessário. Os ensinamentos são feitos, também, pelas próprias artesãs.

Em reuniões periódicas, nas quintas-feiras, a artesã de criação vai ao projeto em Itaitinga, CE, e leva amostras, interage com as artesãs e ensina a confecção de novos pontos. A artesã de criação tem base no bairro Morro de Santa Terezinha, em Fortaleza, onde faz também reuniões com as artesãs desse núcleo. Os produtos são desenvolvidos na Catarina Mina, de acordo com as tendências de moda. As artesãs podem opinar na criação de novos produtos e sugerir melhorias, mas não participam do desenvolvimento das estratégias da empresa. A remuneração das artesãs é variável, paga mensalmente, conforme o volume de produção e volume de vendas. Atendendo as condições de prazo e qualidade definidas pela empresa, a artesã ganha cerca de $\mathrm{R} \$ 35,00$ por

INTERAÇÕES, Campo Grande, MS, v. 18, n. 4, p. 121-135, out./dez. 2017. 
peça produzida (variando para mais ou menos dependendo da dificuldade de produção) e mais $5 \%$ do valor das vendas realizadas pelo website.

\subsection{Reconhecimento e valorização das artesãs}

Os depoimentos coletados indicam que as artesãs se sentem reconhecidas e admiram o trabalho realizado pela Catarina Mina, principalmente em função dos resultados obtidos de aumento na produção de produtos e de aumento nos ganhos financeiros. Contudo, muitas delas não avaliam que a sua profissão é ainda valorizada na comunidade. As artesãs consideram o ofício como uma terapia e gostam de ter uma renda extra para ajudar nos gastos pessoais e da família. Acreditam que o projeto contribuiu para promover a autoestima nas artesãs e criou estímulos sociais positivos, como apontado por Safar e Castro (2011).

A proprietária da empresa faz frequentes visitas às artesãs para apresentar a situação da empresa e as perspectivas de futuro, e para conscientizar sobre a importância do trabalho/ofício. As artesãs não participam das decisões estratégicas, mas são informadas nessas reuniões sobre as decisões e ações a serem implementadas. No website da empresa, existem fotos das artesãs e informações sobre o trabalho/projeto, que geram identificação da marca com o trabalho das artesãs. O website é um canal de vendas dos produtos/bolsas produzidos, possibilita cobrar um preço considerado justo e permite a inserção das artesãs no mercado de trabalho, com valorização e credibilidade (FREEMAN, 2011). Além disto, a empresa utiliza redes sociais (Facebook e Instagram) para ampliar a visibilidade do projeto e seus produtos/artesanatos.

No vídeo institucional da empresa, uma das artesãs comenta: "não é um simples crochezinho, é o nosso trabalho, [...] nossa forma de ganhar a nossa própria remuneração[...] a gente tem reconhecimento". Outra artesã complementa: "[...] hoje o crochê para mim tornou profissão, hoje eu sou artesã, sou crocheteira, antes era passatempo, [...] valorizou muito o trabalho". Como, de modo geral, as artesãs têm renda mensal baixa, esse trabalho de confecção de artesanato possibilita melhorar as condições de vida e a valorização pessoal. Para algumas delas, o artesanato é a principal fonte de remuneração da família; para outras, é uma fonte de remuneração complementar.

Os depoimentos coletados indicam que algumas artesãs começaram no projeto a partir de indicações ou comentários de outros membros da comunidade e que o aumento na demanda dos produtos propiciou novas oportunidades para outras artesãs da comunidade. Além disso, embora algumas artesãs tenham manifestado paixão pela profissão, muitas delas manifestaram que participam do projeto buscando ganhar dinheiro, melhorar seus estudos e para obter meIhores alternativas de vida. O projeto tem pouco mais de seis meses, mas já mostra resultados em termos de expansão de renda e melhora na qualidade de vida das artesãs, como citado por Rech (2009). Contudo as evidências coletadas indicam que não foi criada, ainda, uma cooperativa nem estabelecido políticas de fomento ao desenvolvimento, organização e integração das artesãs, visando dar a sustentabilidade necessária. Há também carência de mecanismos mais formais de planejamento e controle das estratégias e ações envolvidas no projeto.

\subsection{Eficácia do incentivo às artesãs na cadeia de produção}

As artesãs entrevistadas veem o projeto da Catarina Mina como um incentivo eficaz na produção do artesanato. Avaliam que no projeto há atitude proativa da proprietária, e que este 
abrange o fornecedor e parte da comunidade, como proposto por Rech (2009). Entretanto as evidências indicam que o projeto necessita ser aprimorado, pois não envolve outros setores da comunidade nem garante ainda a sustentabilidade das ações envolvidas. Embora tenha havido resistências das artesãs à atuação em cooperativa e a outras formas de ajuda (como de órgãos do governo municipal), os depoimentos coletados indicam que algumas artesãs acreditam que resgatar a antiga associação possibilitaria aprimorar o trabalho e desempenho das artesãs. 0 Quadro 1 resume as principais percepções das artesãs entrevistadas em relação ao projeto da empresa Catarina Mina.

\begin{tabular}{|l|c|}
\hline Como é feito o trabalho da empresa Catarina Mina & Qte. citação \\
\hline Reúnem-se, trocam ideias, cadeia de cooperação & 7 \\
Uma ensina a outra, o que não sabem procuram aprender & 7 \\
Sabem que projeto não tem participação de ONGs ou outros órgãos ou governo & 6 \\
Associação das Artesãs não participa efetivamente, tem descrença em cooperativas & 4 \\
Produzem o pedido pela amostra da empresa & 4 \\
Trabalham em casa & 4 \\
Trabalham em outra atividade também & 4 \\
Artesanato como terapia, prazer & 4 \\
\hline Reconhecimento, valorização e melhora financeira e sustentável após este projeto & Qte. citação \\
\hline Crescendo o número de pedidos, aumento de produção & 7 \\
Gosto, orgulho de ser artesã & 7 \\
Ajuda em casa, melhorou financeiramente, aumentou a renda & 6 \\
Sente-se valorizada dentro do projeto & 6 \\
Sem o projeto voltaria a fazer costura ou mantém o artesanato (mas consideram mais & 4 \\
difícil conseguir vender os produtos por conta própria) & 3 \\
Não saberia o que fazer sem o projeto (se sente dependente dele) & 3 \\
Valorização do trabalho do artesão (por gente de fora) & Qte. citação \\
\hline Eficácia na cadeia produtiva de moda e como pode ser aprimorado & 3 \\
\hline Falta local para capacitação, ensinar, passar conhecimento (exemplo: antiga associação) & 3 \\
Jovens não querem seguir com artesanato, forma temporária para ganhar dinheiro & 2 \\
Categoria não valorizada pelo governo & 2 \\
Transforma a vida de alguém, da comunidade & \\
\hline
\end{tabular}

Quadro 1 - Resultado das entrevistas realizadas

Fonte: Elaborado pelos autores (2015)

Segundo depoimento da proprietária da empresa, o projeto de incentivo implementado possibilitou melhoras no desempenho das artesãs e da comunidade, e a verificação de que os clientes/consumidores estão interessados em produtos de moda consciente e com conceito de sustentabilidade, como apontado por Uniethos (2013). Outro fator importante destacado é a visibilidade do projeto pela loja online e mídias sociais, que colaboram para a motivação e autoestima das artesãs, fazendo com que estas se sintam orgulhosas ao ver sua produção e imagem pessoal postada na internet. Além disto, pelo website, com a divulgação dos custos envolvidos na produção de cada produto, a empresa mostra transparência, não somente para os clientes, mas também para as artesãs. A proprietária entende que o objetivo da empresa não é ser beneficente, mas ser uma organização privada que busca obter lucro nos negócios e promover o incentivo/valorização das artesãs. Há, também, interesse da empresa em ampliar o projeto para outras comunidades na região. 


\subsection{Discussão dos resultados a luz da inovação social}

O projeto das artesãs na cadeia produtiva de moda da empresa Catarina Mina surgiu em função de necessidades da proprietária (ex: interesse em produtos mais atraentes) e da comunidade de artesãs (ex: obter rendimento e valorização). Existe participação e cooperação entre os atores envolvidos, com iniciativas que favorecem a valorização das pessoas/artesãs, conforme aconselha Bignetti (2011). O projeto associa o respeito pessoal ao modo de trabalho das artesãs, o resgate do produto artesanato como objeto de desejo do consumidor e os interesses da empresa.

Embora timidamente, os resultados indicam que o projeto está promovendo o desenvolvimento das artesãs, inclusive com a inserção de jovens mulheres na profissão, como foi identificado na observação de duas artesãs jovens, que iniciaram o trabalho a partir de indicações da comunidade e da entrevista pessoal com uma jovem artesã que lá trabalha há menos de um ano. A possibilidade de inserção de pessoas desfavorecidas pela sociedade é comum em outros segmentos e pode ser considerada uma forma de promoção do desenvolvimento da comunidade (MELO LISBOA, 2005). Os resultados sugerem que houve melhoras na comunidade de artesãs, como reformas de casas, compra de novos tipos de produtos para casa/família e elevação da autoestima e reconhecimento das artesãs. No entanto há ainda dependência em relação à empreendedora do projeto.

No Brasil, a cadeia de produção de moda é, ainda, caracterizada pela informalidade (subcontratação, não cumprimento da legislação, falta de contribuição previdenciária e trabalhadores sem contrato legal) e pela precariedade das condições de trabalho (ambiente degradante, com baixa remuneração e sem direitos trabalhistas), como citado no estudo do Uniethos (2013). No projeto analisado, há preocupação da proprietária em ouvir as artesãs, compartilhar informações e deixá-las trabalhando com prazer e em conformidade com seu estilo de vida, como proposto por Cloutier (2003), ao falar sobre a necessidade de garantir melhor qualidade de vida e equilíbrio entre trabalho e vida. No Quadro 2, algumas informações sobre as dimensões de análise do projeto \#uma conversa sincera, com base em Cloutier (2003).

\begin{tabular}{|l|l|}
\hline $\begin{array}{l}\text { Sua natureza (objeto } \\
\text { em si) }\end{array}$ & $\begin{array}{l}\text { Pode ser visto como sendo tangível, trazendo inovação através dos custos } \\
\text { abertos e participação das artesãs e com o objetivo global de desenvolver a } \\
\text { atividade do artesanato local de forma a beneficiar não somente a empresa, } \\
\text { mas também as artesãs, gerando o seu bem-estar e melhoria de vida. }\end{array}$ \\
\hline $\begin{array}{l}\text { Seu processo de criação } \\
\text { e implementação }\end{array}$ & $\begin{array}{l}\text { Está em processo de implementação e adaptação. Não há diversidade de } \\
\text { atores e participação ativa dos usuários, com processo de aprendizado } \\
\text { definido, mas tem criação de conhecimento pela troca de experiências entre } \\
\text { as artesãs e a empresária. }\end{array}$ \\
\hline Seu alvo de mudanças & $\begin{array}{l}\text { Centrado no indivíduo, buscando recuperar a autoestima da artesã e } \\
\text { a valorização de seu trabalho. Não atinge a coletividade, não traz uma } \\
\text { transformação social duradoura que represente mudanças nas relações e } \\
\text { condições sociais. }\end{array}$ \\
\hline Seus resultados & $\begin{array}{l}\text { Um início de melhora visível na vida e bem-estar das artesãs que trabalham } \\
\text { no projeto, porém não é possível identificar se será uma mudança duradora } \\
\text { nem que conseguirá atingir a comunidade. Falta a cooperação através de } \\
\text { alianças estratégicas, de parcerias ou de redes de diversos atores ou equipes } \\
\text { multidisciplinares. }\end{array}$ \\
\hline
\end{tabular}

Quadro 2 - Dimensões de Análise baseado em Cloutier (2003)

Fonte: Elaborado pelos autores (2015). 
Considerando as lentes/níveis de inovação social propostas por Mulgan, Tucker e Sanders (2007), o Quadro 3 resume as mudanças ocorridas a partir da vigência do projeto, ou seja, síntese de ganhos/melhorias obtidos em nível individual, organizacional e movimentos sociais.

\begin{tabular}{|l|l|}
\hline Indivíduos & $\begin{array}{l}\text { Existe a adoção da lente do indivíduo, pois a proprietária é uma pessoa inspiradora, } \\
\text { persistente, e dedicada, interessada em promover mudança social na comunidade das } \\
\text { artesãs, embora tenha também interesse em obter o lucro necessário para a empresa. }\end{array}$ \\
\hline Movimentos & $\begin{array}{l}\text { Possível notar o crescimento lento entre o pequeno grupo das artesãs, dando início à } \\
\text { lente abordada pelos autores de movimentos sociais. Contudo não consegue ser um } \\
\text { projeto em que as ideias são mais poderosas que o indivíduo. Muito dependente da } \\
\text { gestora. }\end{array}$ \\
\hline Organizações & $\begin{array}{l}\text { Existe uma associação de artesãs, mas esta caiu em descrédito e não está mais em } \\
\text { operação. Falta atualmente um espaço onde as artesãs possam resolver seus próprios } \\
\text { problemas e permitindo promover o empowerment. }\end{array}$ \\
\hline
\end{tabular}

Quadro 3 - Lentes pela visão de Mulgan, Tucker e Sanders (2007)

Fonte: Elaborado pelos autores (2015).

No projeto analisado, a principal contribuição social é permitir que as artesãs tenham orgulho do seu ofício, se sintam valorizadas e tenham melhorias na qualidade de vida, pela ajuda financeira ou aumento na renda familiar. O projeto promoveu, também, a comercialização de produtos/artesanatos através do e-commerce da empresa (website), o que ajuda a atenuar uma das principais dificuldades dos artesãos: a distribuição/vendas dos produtos (FREEMAN, 2011). O projeto promoveu, ainda, a visibilidade das artesãs através de site e redes sociais; as artesãs entrevistadas gostam de ver suas bolsas divulgadas pela internet e curtem as postagens feitas no Facebook e no Instagram.

O projeto analisado está em fase de testar na prática a ideia gerada, de identificar suas faIhas e oportunidades de melhorias (MULGAN; TUCKER; SANDERS, 2007). No entanto é possível perceber que existe ação comunitária, mesmo que pequena e local (GOLDSMITH, 2010), e que o projeto promove a capacitação individual. Por enquanto este parece falhar em não promover mudanças estruturais que permitam a continuidade e o seu crescimento. A transposição da experiência, replicação e expansão para outras comunidades (BIGNETTI, 2011) não acontece, ainda. Avalia-se que, também, não é ainda uma solução douradora para a comunidade, e carece de gestão mais sustentável. Uma parte das artesãs não sabe como sobreviver no caso de o projeto ser encerrado.

A proprietária e colaboradoras diretas da empresa possuem uma visão de inovação social que vai ao encontro do que é preconizado por Cloutier (2003) e Mulgan, Tucker e Sanders (2007), mas o conceito de inovação social compreende a promoção de ações que envolvam as artesãs de maneira mais participativa, gerando maior empowerment e criando menor dependência em relação ao projeto. A integração com outros organismos seria um mecanismo de transformar esse projeto em algo mais duradouro e sustentável. Como o projeto analisado foi implementado recentemente, é possível que, ao longo do seu crescimento e maturação, possa atender as lacunas/falhas identificadas e tornar a ideia/conceito mais poderoso que o indivíduo que a criou (a proprietária) e gerar transformação na comunidade/artesãs de maneira efetivamente sustentável (MULGAN, 2006). 


\section{CONSIDERAÇÕES FINAIS}

O objetivo deste estudo foi analisar se há inovação social na relação entre a rede de produção com artesãos no contexto da cadeia têxtil, no âmbito da loja virtual Catarina Mina. Para tanto, a coleta de dados buscou: identificar como é feito o trabalho da loja Catarina Mina junto aos artesãos; verificar se as artesãs se sentem reconhecidas, valorizadas e obtiveram melhora na situação financeira; identificar se o incentivo na cadeia produtiva possibilitou melhorias sustentáveis na qualidade de vida das artesãs.

Embora os resultados tenham revelado que o projeto analisado tenha soluções inovadoras (como ser a primeira a ter no website os custos detalhados para o consumidor final, inclusive com o valor pago às artesãs), avalia-se que este não atende suficientemente aos critérios de inovação social propostos por Cloutier (2003) e Mulgan, Tucker e Sanders (2007). O caso analisado desenvolve ações que proporcionam a valorização das artesãs e gera melhoras financeiras, bem-estar individual, mas somente para as artesãs que trabalham no projeto. Não há evidências de replicação, expansão e perpetuação dos resultados para outras comunidades. Há, também, forte dependência das artesãs em relação à proprietária da empresa, e não há processo de aprendizado para proporcionar a sustentabilidade na comunidade. Há cooperação entre os atores envolvidos, mas a participação é ainda restrita à criação de conhecimento/habilidades e reduzido esforço de empowerment das artesãs e de promoção do desenvolvimento territorial.

Os resultados deste estudo podem contribuir para a Catarina Mina e outras empresas do setor, interessadas em aprimorar o seu trabalho na cadeia produtiva de moda através de projetos de inovação social. Podem também contribuir para as novas frentes de trabalho que a empresa queira desenvolver, inclusive pelo melhor entendimento sobre o que compreende projetos de inovação social. Em âmbito teórico, o estudo contribuiu para ampliar o conhecimento sobre inovação social no contexto da rede de produção com artesãos na cadeia têxtil. Há evidências detalhadas sobre o trabalho/projeto realizado, aspectos do reconhecimento e valorização das artesãs, e resultados dos incentivos promovidos na cadeia produtiva da empresa analisada.

Como limitações do estudo, cabe destacar que o trabalho analisou apenas uma única empresa/projeto, e o fato de ser esta uma iniciativa recente (ainda em desenvolvimento) pode ter impactado nos resultados do estudo. Como recomendações para futuros estudos, sugere-se ampliar a quantidade de casos/projetos de inovação social analisados (estudo de casos múltiplos), analisar projetos inovadores e sociais na cadeia de fornecimento de outros setores e analisar quais incentivos geram mais desenvolvimento, sustentabilidade e transformação na comunidade. Há, ainda, necessidade de propor uma agenda de internalização de inovações sociais em empresas varejistas atuantes em rede.

\section{REFERÊNCIAS}

BARDIN, Laurence. Análise de conteúdo. Lisboa: Edições 70, 1977.

BIGNETTI, Luiz Paulo. As inovações sociais: uma incursão por ideias, tendências e focos de pesquisa. Ciências Sociais Unisinos, São Leopoldo, RS, v. 47, n. 1, p. 3-14, jan./abr. 2011.

CATARINA MINA. [s.d.]. Disponível em: <http://www.catarinamina.com/sobre-pg-3249f>. Acesso em: 10 jul. 2015.

CHIAVEnATO, Idalberto. Princípios da Administração: o essencial em teoria geral da administração. 2. ed. Barueri, SP : Manole, 2012. 
CLOUTIER, J. Qu'est-ce que l'innovation sociale? In: CRISES - Centre de Recherche Sur Les Innovations Sociales. Les Cahiers du CRISES. Québec, 2003. Disponível em: <https://crises.uqam.ca/upload/files/ publications/etudes-theoriques/CRISES_ETO314.pdf>.

COUTINHO, L.; FERRAZ, J. C. (Coord.). Estudo da competitividade da indústria brasileira. Relatório Final. IE/UNICAMP- IEI/UFRJ- FDC- FUNCEX, 1993. Disponível em: <http://livros01.livrosgratis.com.br/ci000038. pdf>. Acesso em: 3 ago. 2015

CRESWELL, J. W. Projeto de pesquisa métodos qualitativo, quantitativo e misto. Porto Alegre, RS: Artmed, 2010.

DUARTE, M. F.; SILVA, A. L. A experimentação do risco na carreira criativa: o caso de mestres da cultura do artesanato cearense. Revista Eletrônica de Ciência Administrativa (RECADM), v. 12, n. 2, p. 22-38, maio/ago. 2013. Disponível em: <http://www.spell.org.br/documentos/ver/11058/>. Acesso em: 7 ago. 2015.

FACHINELLI, Ana Cristina; D’ARISBO, Anelise; MACIEL, Erick de Melo. A importância da inovação social e da economia criativa como indutores para o desenvolvimento sustentável. International Journal of Knowledge Engineering and Management (IJKEM), Florianópolis, v. 3, n. 5, p. 276-93, mar./jun. 2014. Disponível em: <http://incubadora.periodicos.ufsc.br/index.php/IJKEM/article/view/2687/3269>.

FELIPPSEN, B. Sustentabilidade à mão. Revista Especial Fortaleza, abr. 2012.

FREEMAN, C. S. Economia do artesanato. 2011. Disponível em:<http://clairesf.wordpress.com/artigos-2/ economia-do-artesanato/> Acesso em: 7 jul. 2015.

GOLDSMITH, S. The power of social innovation: how civic entrepreneurs ignite community networks for Good. San Francisco: Jossey-Bass, 2010. 307p.

ITAITINGA, Governo Municipal [de]. Plano municipal de educação. 2014. Disponível em: <http://www. funcepe.org.br/wp-content/uploads/2015/07/HIST\%C3\%93RIA-DO-MUNICIPIO-DE-ITAITINGA.pdf>. Acesso em: 12 nov. 2016.

JULIANI; Douglas Paulesky; JULIANI, Jordan Paulesky; SOUZA, João Artur de; HARGER, Eliza Malucelli. Inovação social: perspectivas e desafios. Espacios, v. 35, n. 5, 2014.

LOURENÇO, Cléria Donizete da Silva. Cultura brasileira e marketing de relacionamento: um estudo etnográfico no varejo. Revista Brasileira de Marketing, v. 13, n. 5, p. 47-64, jul./set. 2014. Disponível em: <http://www.revistabrasileiramarketing.org/ojs-2.2.4/index.php/remark/article/view/2395/pdf_180>.

MAURER, A. M.; SILVA, T. N. Dimensões analíticas para identificação de inovações sociais: evidências de empreendimentos coletivos. Brazilian Business Review, v. 11, n. 6, p. 127-50, 2014.

MELO LISBOA, Armando de. Economia solidária e autogestão: imprecisões e limites. RAE - Revista de Administração de Empresas, São Paulo, v. 45, n. 3, p. 109-15, jul./set. 2005.

MINISTÉRIO DO DESENVOLVIMENTO INDÚSTRIA E COMÉRCIO EXTERIOR (MDIC). Portaria n. 29, de 5 de outubro de 2010. Diário Oficial da União, Brasília, n. 192, 6 de outubro de 2010. Seção 1. Disponível em: <http://www.legisweb.com.br/legislacao/?id=221568> Acesso em: 6 ago. 2015.

MULGAN, Geoff. The process of social innovation. Innovations: Technology, Governance, Globalization, v. 1, n. 2, p. 145-62, 2006. Disponível em: <http://www.mitpressjournals.org/doi/pdf/10.1162/ itgg.2006.1.2.145>.

MULGAN, Geoff; TUCKER, Simon; SANDERS, Ben. Social innovation: what it is, why it matters and how it can be accelerated. Skoll Centre for social entrepreneurship. London: The Young Foundation, 2007.

OKADA, Regina Akemi; BERLIM, Lilyan. Design de moda: possibilidades de inovação social e sustentabilidade. Iniciação - Revista de Iniciação Científica, Tecnológica e Artística, v. 4, n. 2, maio 2014.

PEREIRA, C. J. C. Artesanato: definições, evolução e ação do Ministério do Trabalho; o programa nacional de desenvolvimento do artesanato. Brasília: MTB, 1979. 153p. 
RECH, Sandra Regina. Modelo conceitual de análise competitiva em micro e pequenas empresas do setor de confecções. UNOPAR Científica, Revista de Ciências Jurídicas e Empresariais, Londrina, PR, v. 10, n. 1, p. 5-12, mar. 2009.

SACHS, I. Desenvolvimento: includente, sustentável sustentado. Rio de Janeiro: Garamond, 2008.

SAFAR, G. H.; CASTRO, C. G. A contribuição das experiências com projetos artesanais para o desenvolvimento da criatividade e do conhecimento das empresas. Revista Design, Arte, Moda e Tecnologia, São Paulo, 7. ed., nov. 2011. Disponível em: <http://sitios.anhembi.br/damt/?p=239>. Acesso em: 7 ago. 2015.

SERVIÇO DE APOIO ÀS MICRO E PEQUENAS EMPRESAS (SEBRAE). Artesanato: um negócio genuinamente brasileiro. Brasília: SEBRAE, 2008. v. 1, n. 1.

UNIETHOS. Sustentabilidade e competitividade na cadeia da moda. São Paulo, maio de 2013. Disponível em: <http://www.abit.org.br/conteudo/links/estudo_sustentabilidade_uniethos.pdf>.

YIN, Robert K. Estudo de caso: planejamento e métodos. 4. ed. Porto Alegre: Bookman, 2010.

\section{Sobre os autores:}

Aline Silva Autran de Morais: Mestre em Administração pela Universidade do Sul de Santa Catarina (UNISUL). MBA em Gestão Empresarial (Major) e Marketing de Serviços (Minor) pela Escola Superior de Propaganda e Marketing (ESPM). MBA em Gestão em Varejo (FGV/ $\mathrm{SP}$ ) in Company. Especialização em Marketing (FGV/RJ). Graduação em Comunicação Social pela UFRGS (1994). Experiência na área de Administração, com ênfase em Varejo. E-mail: alineautran@ideiamais.com.br

Simone Sehnem: Doutora em Administração e Turismo pela Universidade do Vale do Itajaí (UNIVALI). Professora no Mestrado de Administração na UNISUL e Professora Titular na Universidade do Oeste de Santa Catarina (UNOESC).E-mail: simonesehnem_adm@yahoo.com.br

Aléssio Bessa Sarquis: Doutor em Administração pela FEA/USP. Professor no Mestrado de Administração na UNISUL. E-mail: alessio.sarquis@gmail.com

Taisa Dias: Doutora em Administração pela Universidade Federal de Santa Catarina (UFSC). Professora na UFSC. E-mail: taisadias.adm@gmail.com 
